\title{
Music Therapy Effects in People with Dementia
}

\author{
Martina Pigliautile ${ }^{1}$, Francesco Delicati ${ }^{2}$, Roberta Cecchetti ${ }^{1}$, Patrizia Bastiani ${ }^{1}$, Michela Scamosci ${ }^{1}$, Simonetta \\ Cesarini $^{3}$, Giuseppe Menculini ${ }^{4}$, Annalisa Longo ${ }^{1,2}$, Patrizia Mecocci ${ }^{1}$ and Stefano Federici ${ }^{5 *}$
}

${ }^{1}$ Section of Gerontology and Geriatrics, Department of Medicine, Perugia, Italy

${ }^{2}$ A.M.A.T.A. UMBRIA, Perugia

${ }^{3}$ Residenza Protetta Fontenuovo, Perugia, Italy

${ }^{4}$ Residenza Protetta Creusa Brizzi Bittoni, Città della Pieve, Perugia, Italy

${ }^{5}$ Department of Philosophy, Social \& Human Sciences and Education, University of Perugia, Perugia, Italy

*Corresponding author: Stefano Federici, Department of Philosophy, Social \& Human Sciences and Education, Perugia, Italy

\begin{abstract}
Objective: Based on the biopsychosocial model, we developed a paradigm to explore if music therapy (MT) is effective in increasing the well-being of persons with dementia.

Method: A randomized controlled trial, mixed method design was used. Twenty-seven persons with moderate/severe dementia split into an experimental ( $\mathrm{n}=16$; MT and standard care) and a control $(\mathrm{n}=11$; standard care only) group were subjected to a cycle of MT weekly sessions for five months. Quantitative levels of salivary cortisol, health status (body functioning and structures and health-related states), and outcome measures (psycho-behavioral disturbances and quality of life) were associated with qualitative analysis of the participants' behavior during MT sessions.

Results: The study showed that MT is effective in reducing psycho-behavioral disturbances and maintaining a good quality of life. No apparent effects were found with respect to the level of salivary cortisol. Qualitative analysis is very effective for obtaining information on patient behavior during the MT.
\end{abstract}

Conclusions: The paradigm was suitable to integrate quantitative and qualitative data on the effectiveness of MT interventions.

Keywords: Dementia; Music Therapy; Quality of Life; Geriatric Assessment; Biopsychosocial Model, Cortisol

\section{Introduction}

The effectiveness of music therapy (MT) in the management of behavioral and psychological symptoms of dementia (BPSD) is well documented in the literature [1-8]. However, evidence for the efficacy of MT in dementia is still inconclusive [9]. The lack of evidence-based practice in MT for dementia has been noted by several scholars [10-13], who also found methodological limitations across the studies $[5,14,15]$ and biases due to unspecified criteria in participant selection to the studies, small sample size, lack of randomization and blinded evaluation, group dissimilarity at baseline, no test-retest studies, and lack of a control group [16]. Researchers must face a twofold challenge: a. adopt a research method able to mix quantitative and qualitative data that come from the interacting and complex domains of human functioning and affect the progressive and unpredictable course of dementia;

b. select a homogenous sample able to be representative of the studied condition (dementia), so different from individual to individual. With regard to the first point, according to the geriatric medicine, the health status of older people with dementia and therefore the effectiveness of the MT should be evaluated using the Comprehensive Geriatric Assessment (CGA) [17]. This multidimensional, multidisciplinary diagnostic instrument 
was designed to collect data on the medical, psychosocial, and functional capabilities and limitations of older patients. The geriatric assessment differs from a standard medical evaluation because it takes into account also nonmedical domains emphasizing functional ability and quality of life. So, the CGA is very compatible with the International Classification of Functioning, Disability, and Health (ICF) based on the biopsychosocial model [18].

In fact, both the CGA and the biopsychosocial model are focused on human functioning as a person-environmental interaction and integrating medical, psychological, and social models of human functioning. As it was highlighted [19,20], the CGA and ICF models include similar assessment domains: health condition, body functions and structures, activities, participation, and contextual factors, and share a common approach to the assessment of the person as a whole within the context of both person's capacities and expectations and supportive resources of the environment. The second challenge posed to researchers is strongly correlated to the first one. Because of the large number of variables affecting the health status of people with dementia and the substantial individual differences in the course of dementia, the scholar should remain cautious in generalizations, provide clear patient anamnestic descriptions, and develop a longitudinal design to control individual variability in the course of the disease to control what characterizes individual history with respect to the effectiveness of the MT intervention [3]. Innovative paradigms and research protocol have been recently presented and mixed method [21]. have been used in order to capture MT effects.

\section{Study Paradigm}

To overcome those challenges, the present study developed a paradigm to assess the effectiveness of an MT treatment in people with moderate/severe dementia, by adopting a biopsychosocial and CGA perspective. A mixed method randomized controlled trial experiment was designed to gather quantitative data on cognitive reserve, severity of dementia, comorbidity, cognitive and physiological functions, and psychological functioning and behavior, and qualitative data involving the phenomenological observation of the MT interventions.

\section{Expected Results}

To dispose of a paradigm able to study music therapy effects in participants with dementia. To demonstrate the usefulness of our paradigm to explore if MT is effective, we expect to observe the following results;

a) Those who receive MT should have a lower level of BPSD, as measured by the Neuropsychiatric Inventory (NPI), CohenMansfield Agitation Inventory (CMAI), and Cornell Scale for Depression in Dementia (CDS) than the control group. This result was expected from studies founding that MT is useful for the management of BPSD in older people with dementia [2,9,22] b) Those receiving MT will have a higher quality of life (QOL) than those in the control group. QOL was identified as a central goal in the treatment of dementia $[11,23]$. This result will replicate previous studies that correlated MT with QOL of people with dementia $[1,9,12,15]$.

c) Those receiving MT will have a lower level of salivary cortisol, indicative of a lower level of stress, than those in the control group. This result will replicate a previous study by Suzuki et al. [24]. who found a diminished secretion of cortisol correlated with positive psychological well-being in people with dementia.

d) Those receiving MT will be able to recognize nonverbal signs. This result will replicate previous studies finding that MT is effective for expanding group participation, archaic expressive, and relational nonverbal abilities in those with moderate/severe dementia $[2,25]$.

\section{Method}

\section{Participants}

The study was a mixed method single-blinded randomized controlled trial performed in two Italian nursing homes. The protocol was approved by the Bioethics Committee of the University of Perugia (MUSIC14). Inclusion and exclusion criteria were established by a consensus of experts (geriatricians and psychologists). Inclusion criteria were:

a. Diagnosis of Alzheimer or vascular dementia or mixed dementia, defined according to the Diagnostic and Statistical Manual of Mental Disorders: DSM-IV-TR criteria (DSM-IV [26];

b. Moderate or severe stage of dementia according to the Clinical Dementia Rating [27]: score from 2 to 3;

c. Scores between 0 and 20 on the Mini Mental State Examination [28].

Exclusion criteria were;

I. Wandering;

II. Diagnosis of frontotemporal dementia;

III. Diagnosis of Levy body dementia;

IV. Vegetative state;

V. Use of corticosteroids.

Informed consent was obtained from proxies.

Experimental (EG) and control groups (CG) were formed in the nursing homes. CG participants from each nursing home were treated with usual activities (group games, arts, motor or sensorial stimulation). EG participants were also involved in the usual activities when not involved in music therapy. S.F., not involved in the assessment, randomly assigned participants to CG or EG. A simple randomization was used. 


\section{Experimental Condition}

The program consisted of 20 MT sessions: once a week for 60 min. per session over 5 months. The model of the intervention [29] belongs to the humanistic MT [30-32] The MT intervention can be ascribed among the active techniques, characterized by direct interactions with participants using musical improvisation with the aim of stimulating communication skills, improving relational abilities, and reducing BPSD [33]. The intervention was conducted in a structured therapeutic setting, in a large and quiet room of the nursing home where participants dwelled. Music therapy was conducted by a professional music therapist together with a formal caregiver of the nursing home. Number of participants was 10 in a nursing home and 6 in the other.

\section{Measures}

Quantitative and qualitative data were collected in the manner summarized in Table 1. These measures consisted of the following:

Table 1: Timetable of experimental procedure and timing of measures collection.

\begin{tabular}{|c|c|c|c|c|c|c|c|c|c|c|c|c|}
\hline & \multicolumn{3}{|c|}{ Pre-MT } & \multicolumn{6}{|c|}{ MT } & \multicolumn{3}{|c|}{ Post-MT } \\
\hline TIME & T0 & T1 & $\mathbf{T} 2$ & T3 & T4 & T5 & T6 & T7 & T8 & T9 & T10 & T11 \\
\hline \multirow{6}{*}{$\begin{array}{l}\text { Health status } \\
\text { measures }\end{array}$} & C-Int & & & & & & & & & & & \\
\hline & CDR & & & & & & & & CDR & & & CDR \\
\hline & CIRS-s/c & & & & & & & & CIRS-s/c & & & CIRS-s/c \\
\hline & MMSE & & & MMSE & & & & & MMSE & & & MMSE \\
\hline & WHODAS 2.0 & & & & & & & & WHODAS 2.0 & & & WHODAS 2.0 \\
\hline & ADCS-ADL & & & $\begin{array}{c}\text { ADCS- } \\
\text { ADL }\end{array}$ & & & ADCS-ADL & & ADCS-ADL & & & ADCS-ADL \\
\hline \multirow{8}{*}{$\begin{array}{l}\text { Outcome } \\
\text { measures }\end{array}$} & NPI & & & NPI & & & NPI & & NPI & & & NPI \\
\hline & CMAI & & & CMAI & & & CMAI & & CMAI & & & CMAI \\
\hline & CDS & & & CDS & & & CDS & & CDS & & & CDS \\
\hline & QOL-P & & & QOL-P & & & & & QOL-P & & & QOL-P \\
\hline & QOL-C & & & QOL-C & & & & & QOL-C & & & QOL-C \\
\hline & & & & \multicolumn{6}{|c|}{ MT sessions (S1-S20) } & & & \\
\hline & $\mathrm{CO}$ & & & \multicolumn{6}{|c|}{ S2; S11; S20 } & & & \\
\hline & Microanalysis & & & \multicolumn{6}{|c|}{ S1; S2; S5; S7; S10; S11; S14; S16; S19; S20 } & & & \\
\hline
\end{tabular}

ADCS-ADL = Alzheimer Disease Cooperative Study-Activities of Daily Living; CDR = Clinical Dementia Rating Scale; CDS = Cornell Depression Rating Scale; CIRS-s/c = Cumulative Illness Rating Scale severity/comorbidity; CMAI = Cohen-Mansfield Agitation Inventory; $\mathrm{CO}=$ salivary cortisol level; grey = MT sessions; Microanalysis = sessions video analyzed; MMSE = Mini Mental State Examination (row score); NPI = Neuropsychiatric Inventory; QOL-C = Quality of Life Alzheimer Disease caregiver version; QOL-P $=$ Quality of Life Alzheimer Disease patient version; $\mathrm{S}=$ music therapy session; $\mathrm{T}=$ month of the experimental phase; WHODAS 2.0 = World Health Organization Disability Assessment Schedule 2.0.

I. Clinical Interview on Socio-Demographic and Clinical Data (C-Int): An interviewer asked participants questions about cultural person capital (cognitive reserve index), medical history, and pharmacological treatment.

II. Cortisol Biological Marker (CO): The measure of salivary cortisol level (CO) was performed on unstimulated whole saliva collected from passive drooling. Unstimulated whole saliva is the baseline saliva present in the oral cavity for the majority of a 24hour period. To avoid variations due to circadian rhythm, saliva specimens were taken at a fixed time, immediately before the MT session (10 a.m.) and immediately after the session (11 a.m.) in both groups.

III. Cumulative Illness Rating Scale (CIRS) [34]: It is a summary measure of illness severity (CIRS-s) and comorbidity (CIRS-c).
IV. Clinical Dementia Rating (CDR) [27]: is a global staging measure of dementia.

V. Mini Mental State Examination (MMSE) [28]: This is the most commonly used screening test of cognitive functions.

VI. Alzheimer Disease Cooperative Study-Activities of Daily Living (ADCS-ADL) [35]: This is an inventory to assess activities of daily living for clinical trials in dementia.

VII. World Health Organization Disability Assessment Schedule 2.0 (WHODAS 2.0) [36,37]: Generic assessment instrument to provide a standardized cross-cultural method for measuring activity limitations and participation restrictions, largely employed in geriatric settings [38]. The Italian 12-item version of the WHODAS 2.0 interviewer-administered proxy form was used [37]. The simple scoring option was adopted [36]. 
VIII. Neuropsychiatric Inventory (NPI) [39]: assesses neuropsychiatric disturbances common in dementia together with the amount of caregiver distress engendered by each of the neuropsychiatric disorders.

IX. Cornell Scale for Depression in Dementia (CDS) [40]: Clinician-administered instrument that uses information from interviews with both the patient and an informant to evaluate depression in dementia. It was also validated in patients with moderate to severe dementia [41].

X. Cohen-Mansfield Agitation Inventory (CMAI) [42]: In this questionnaire, caregivers rate the frequency of manifestations of agitated behaviors in elderly persons. The Italian 30-item proxy version $[43,44]$. was administered.

XI. The Quality of Life - Alzheimer's Disease scale (QOLAD) [45]: Developed for individuals with dementia, it comprises both a version for the person with dementia (QOL-P) and a version for the caregiver (QOL-C).

XII. Microanalysis on MT sessions' Video Clips (Microanalysis) [46,47]: This is a five-step procedure for video analysis to investigate the communicative response of a specific client in a music therapy treatment. A consensus of experts (music therapist and psychologist) developed criteria to identify the patient's and music therapist's salient behaviors (e.g., when the patient joins in singing, plays, smiles, shows a gaze orientation, spontaneously moves their body, etc.) during MT intervention (videotaped). A trained group of psychology students analyzed the video of the MT sessions. Starting from the results of this analysis, the music therapist composed a video clip consisting of the most salient moments of the therapy of each participant. The microanalysis provides a clear distinction between description, observation, personal reflections, and interpretations of the clip content. The assessment measures (CDR, MMSE, ADCS-ADL, NPI, CDS, CMAI) were adopted to comprehensively cover the geriatric assessment domains of the CGA [17], in fact these are extensively employed in geriatric medicine.

\section{Procedure}

The study covers a period of twelve months (T0-T11). Twenty music therapy sessions (S1-S20) were administered to two experimental groups, once a week in the morning, for $60 \mathrm{~min}$. per session over 5 months (T3-T8), starting three months after the patient eligibility assessment (T0). The MT treatment was evaluated longitudinally four times: (i) at the beginning of the MT treatment (T3), (ii) at the beginning of the fourth month of treatment (T6), (iii) at the end of the MT treatment (T8), (iv) and three months after the MT treatment (T11). Salivary cortisol fluid was sampled at the time of the second MT session (S2), midway through the sessions (S11), and at the time of the last session (S20). Samples were taken at fixed times, to avoid variations due to circadian rhythms: immediately before the beginning of the MT session (10:00 a.m.) and immediately after (11:00 a.m.). Those in the control group had salivary fluid sampled on the same days and at the same times. Ten out of 20 MT sessions (S1; S2; S5; S7; S10; S11; S14; S16; S19; S20) were also videotaped for the microanalysis. As Microanalysis is a very long procedure, it was conducted limited to three clinical case casually chosen from the EG. Geriatricians provided information on the personal and clinical history (C-Int) severity of dementia (CDR) and comorbidity (CIRS). Caregivers were interviewed to obtain their assessments of the patients/participants neuropsychiatric symptoms (NPI, CDS, CMAI), functional status (ADCS-ADL), quality of life (QOL-C), and activity limitations and participation restrictions (WHODAS 2.0). Patients were assessed on the cognitive status (MMSE) and quality of life (QOL-P). Three biologists were involved in the salivary cortisol level analysis. Table 1 summarizes the timing of measures collection. The professional administering interviews and measures and respondents involved in the study were blind to patients' membership in the EG or CG. The music therapist was unaware of the changes in cognitive, functioning, and behavioral status measured during the study (Table 1).

\section{Analysis}

Mann-Whitney and Wilcoxon tests were performed on health status and outcome measures. Statistical significance was defined as $\mathrm{p} \leq 0.05$ [48]. On biological measures, a t-test was also conducted, using the bootstrap method. Analyses were performed through IBM - Statistical Package for the Social Sciences, version 24 for Windows, Armonk, NY. Qualitative data were inserted into an Excel file according to the Microanalysis guidelines developed by Ridder [46].

\section{Results}

\section{Demographic}

A total of 27 people with dementia were enrolled and blinded randomized into the $\mathrm{CG}(\mathrm{n}=11$; male $=3$; mean age $=83.36 \pm 9.19$; mean education in years $=6.91 \pm 4.50)$ and $\mathrm{EG}(\mathrm{n}=16$; male $=3$; mean age $=85.94 \pm 8.54$; mean education in years $=4.75 \pm 3.00)$. No differences in health status measures and outcome measures were found between the CG and EG at baseline. Four patients died during the study and two were hospitalized. So for these cases, some data are missing.

\section{Health Status}

The analysis reveals a worsening of dementia severity (CDR) together with an improvement on activities of daily living (ADCS$\mathrm{ADL}$ ) in the EG: the CDR score in the T0 vs. T8 comparison ( $\mathrm{p}=$ $0.046)$ significantly increased. The ADCS-ADL score significantly decreased from T0 to T3 $(p=0.020)$ and T6 to T8 $(p=0.003)$ and significantly increased from T0 to $\mathrm{T} 6(\mathrm{p}=0.049)$ and $\mathrm{T} 3$ to $\mathrm{T} 6$ $(p=0.003)$. No differences were found on the health status measures in the CG. 


\section{Outcome}

\section{QOL-P}

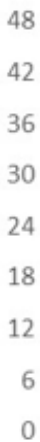

$\begin{array}{llll}\text { T0 } & \text { T3 } & \text { T8 }\end{array}$

Figure 1: Significant differences between EG and CG on outcome measures detected with Wilcoxon non-parametric statistic. The horizontal axis indicates month of the experimental phase $(\mathrm{T})$; the vertical axis indicates QOL scores (range 0-48, the higher scores, the better QOL-AD).

Table 2: Differences in health status and outcome measures between samples using Wilcoxon non-parametric statistic.

\begin{tabular}{|c|c|c|c|c|c|c|c|c|c|c|c|}
\hline Measures & Group & T0 & & T3 & & T6 & & T8 & & T11 & \\
\hline \multicolumn{12}{|c|}{ Health status measures } \\
\hline \multirow[t]{2}{*}{ CDR } & $\mathrm{EC}$ & $\begin{array}{c}2.31 \\
(0.70)\end{array}$ & \multirow{2}{*}{$\mathrm{p}=0.753$} & & & & & $2.56(0.63)$ & (2) & $\begin{array}{c}2.40 \\
(0.74)\end{array}$ & \multirow{2}{*}{$\mathrm{p}=0.482$} \\
\hline & CG & $\begin{array}{c}2.27 \\
(0.47)\end{array}$ & & & & & & $2.80(0.92)$ & $p=0.816$ & $\begin{array}{c}2.67 \\
(0.50)\end{array}$ & \\
\hline \multirow[t]{2}{*}{ CIRS-s } & EG & $\begin{array}{c}1.81 \\
(0.38)\end{array}$ & \multirow{2}{*}{$\mathrm{p}=0.422$} & & & & & $1.82(0.41)$ & \multirow{2}{*}{$\mathrm{p}=0.770$} & $\begin{array}{c}1.82 \\
(0.41)\end{array}$ & \multirow{2}{*}{$\mathrm{p}=0.907$} \\
\hline & CG & $\begin{array}{c}1.70 \\
(0.43)\end{array}$ & & & & & & $1.79(0.43)$ & & $\begin{array}{c}1.81 \\
(0.41)\end{array}$ & \\
\hline \multirow[t]{2}{*}{ CIRS-c } & EG & $\begin{array}{c}3.94 \\
(1.77)\end{array}$ & \multirow{2}{*}{$\mathrm{p}=0.753$} & & & & & $3.93(1.87)$ & \multirow{2}{*}{$p=0.726$} & $\begin{array}{c}3.93 \\
(1.87)\end{array}$ & \multirow{2}{*}{$p=0.640$} \\
\hline & CG & $\begin{array}{c}3.54 \\
(2.38)\end{array}$ & & & & & & $4.11(2.37)$ & & $\begin{array}{c}4.22 \\
(2.22)\end{array}$ & \\
\hline \multirow[t]{2}{*}{ MMSE } & $\mathrm{EC}$ & $\begin{array}{l}12.57 \\
(5.89)\end{array}$ & \multirow{2}{*}{$\mathrm{p}=0.145$} & $\begin{array}{l}11.93 \\
(3.73)\end{array}$ & \multirow{2}{*}{$\mathrm{p}=0.369$} & & & $\begin{array}{l}12.78 \\
(4.30)\end{array}$ & \multirow{2}{*}{$\mathrm{p}=0.482$} & $\begin{array}{l}11.67 \\
(3.70)\end{array}$ & \multirow{2}{*}{$\mathrm{p}=0.270$} \\
\hline & CG & $\begin{array}{l}16.12 \\
(4.42)\end{array}$ & & $\begin{array}{l}13.44 \\
(4.88)\end{array}$ & & & & $\begin{array}{l}14.25 \\
(4.13)\end{array}$ & & $\begin{array}{l}13.87 \\
(4.80)\end{array}$ & \\
\hline \multirow[t]{2}{*}{$\begin{array}{c}\text { WHODAS } \\
2.0\end{array}$} & EG & $\begin{array}{c}21.00 \\
(10.83)\end{array}$ & \multirow{2}{*}{$\mathrm{p}=0.452$} & & & & & $\begin{array}{l}23.87 \\
(5.95)\end{array}$ & \multirow{2}{*}{$p=0.610$} & $\begin{array}{l}18.31 \\
(9.09)\end{array}$ & \multirow{2}{*}{$\mathrm{p}=0.422$} \\
\hline & CG & $\begin{array}{c}24.00 \\
(10.19)\end{array}$ & & & & & & $\begin{array}{l}24.18 \\
(9.43)\end{array}$ & & $\begin{array}{c}19.09 \\
(12.98)\end{array}$ & \\
\hline \multirow[t]{2}{*}{$\begin{array}{c}\text { ADCS- } \\
\text { ADL }\end{array}$} & EG & $\begin{array}{c}10.47 \\
(12.13)\end{array}$ & \multirow{2}{*}{$\mathrm{p}=0.180$} & $\begin{array}{c}8.31 \\
(11.17)\end{array}$ & \multirow{2}{*}{$\mathrm{p}=0.336$} & $\begin{array}{c}12.06 \\
(12.83)\end{array}$ & \multirow{2}{*}{$\mathrm{p}=0.135$} & $\begin{array}{c}9.47 \\
(11.88)\end{array}$ & \multirow{2}{*}{$p=0.567$} & $\begin{array}{l}10.76 \\
(9.79)\end{array}$ & \multirow{2}{*}{$p=0.456$} \\
\hline & CG & $\begin{array}{c}5.63 \\
(4.72)\end{array}$ & & $\begin{array}{c}6.70 \\
(7.99)\end{array}$ & & $\begin{array}{c}6.90 \\
(6.31)\end{array}$ & & $6.00(5.39)$ & & $\begin{array}{c}7.25 \\
(3.95)\end{array}$ & \\
\hline \multicolumn{12}{|c|}{ Outcome measures } \\
\hline & & T0 & & T3 & & T6 & & T8 & & T11 & \\
\hline \multirow[t]{2}{*}{ NPI } & EG & $\begin{array}{c}21.40 \\
(18.44)\end{array}$ & \multirow{2}{*}{$\mathrm{p}=0.760$} & $\begin{array}{c}14.50 \\
(12.18)\end{array}$ & \multirow{2}{*}{$\mathrm{p}=0.942$} & $\begin{array}{c}12.31 \\
(11.39)\end{array}$ & \multirow{2}{*}{$\mathrm{p}=0.586$} & $\begin{array}{c}17.50 \\
(14.02)\end{array}$ & \multirow{2}{*}{$p=0.136$} & $\begin{array}{c}21.13 \\
(17.74)\end{array}$ & \multirow{2}{*}{$p=0.392$} \\
\hline & CG & $\begin{array}{c}22.00 \\
(15.39)\end{array}$ & & $\begin{array}{l}13.36 \\
(9.40)\end{array}$ & & $\begin{array}{c}14.60 \\
(12.00)\end{array}$ & & $9.22(9.36)$ & & $\begin{array}{c}19.12 \\
(27.32)\end{array}$ & \\
\hline
\end{tabular}




\begin{tabular}{|c|c|c|c|c|c|c|c|c|c|c|c|}
\hline CMAI & EG & $\begin{array}{c}42,67 \\
(10.21) \\
\end{array}$ & \multirow{2}{*}{$\mathrm{p}=0.838$} & $\begin{array}{c}41,13 \\
(11.37)\end{array}$ & \multirow{2}{*}{$\mathrm{p}=0.897$} & $\begin{array}{c}36,13 \\
(7.60) \\
\end{array}$ & \multirow[b]{2}{*}{$p=0.637$} & $\begin{array}{c}41,69 \\
(10.87) \\
\end{array}$ & \multirow{2}{*}{$\mathrm{p}=0.241$} & $\begin{array}{c}44,53 \\
(14.00)\end{array}$ & \multirow[b]{2}{*}{$p=0.591$} \\
\hline & CG & $\begin{array}{c}43,00 \\
(11.16)\end{array}$ & & $\begin{array}{c}40,20 \\
(10.56)\end{array}$ & & $\begin{array}{l}38,22 \\
(9.13)\end{array}$ & & $\begin{array}{l}35,90 \\
(8.03)\end{array}$ & & $\begin{array}{c}40,88 \\
(12.44)\end{array}$ & \\
\hline \multirow[t]{2}{*}{ CDS } & EG & $\begin{array}{c}6.33 \\
(4.67)\end{array}$ & \multirow{2}{*}{$\mathrm{p}=0.305$} & $\begin{array}{c}3.62 \\
(4.18)\end{array}$ & \multirow{2}{*}{$\mathrm{p}=0.421$} & $\begin{array}{c}1.33 \\
(2.26)\end{array}$ & \multirow{2}{*}{$p=0.428$} & $1.94(2.43)$ & \multirow{2}{*}{$\mathrm{p}=0.979$} & $\begin{array}{c}0.78 \\
(1.48)\end{array}$ & \multirow{2}{*}{$p=0.402$} \\
\hline & CG & $\begin{array}{c}7.36 \\
(3.61) \\
\end{array}$ & & $\begin{array}{c}4.10 \\
(2.92)\end{array}$ & & $\begin{array}{c}3.20 \\
(4.621) \\
\end{array}$ & & $4.00(7.15)$ & & $\begin{array}{c}3.00 \\
(5.18) \\
\end{array}$ & \\
\hline \multirow[t]{2}{*}{ QOL-P } & EG & $\begin{array}{l}31.12 \\
(4.55) \\
\end{array}$ & \multirow{2}{*}{$\mathrm{p}=0.755$} & $\begin{array}{l}32.75 \\
(6.80) \\
\end{array}$ & \multirow{2}{*}{$p=0.622$} & & & $\begin{array}{l}32.85 \\
(9.87) \\
\end{array}$ & \multirow{2}{*}{$\mathrm{p}=0.053$} & $\begin{array}{l}33.00 \\
(6.62) \\
\end{array}$ & \multirow{2}{*}{$p=0.254$} \\
\hline & CG & $\begin{array}{c}30.17 \\
(9.51) \\
\end{array}$ & & $\begin{array}{c}35.80 \\
(10.87)\end{array}$ & & & & $\begin{array}{l}20.71 \\
(9.03) \\
\end{array}$ & & $\begin{array}{l}29.40 \\
(5.68)\end{array}$ & \\
\hline \multirow[t]{2}{*}{ QOL-C } & EG & $\begin{array}{l}32.07 \\
(6.04) \\
\end{array}$ & \multirow{2}{*}{$\mathrm{p}=0.164$} & $\begin{array}{l}32.81 \\
(6.48) \\
\end{array}$ & \multirow{2}{*}{$\mathrm{p}=0.065$} & & & $\begin{array}{l}30.75 \\
(6.04) \\
\end{array}$ & \multirow{2}{*}{$\mathrm{p}=0.310$} & $\begin{array}{l}31.93 \\
(5.94) \\
\end{array}$ & \multirow{2}{*}{$\mathrm{p}=0.070$} \\
\hline & CG & $\begin{array}{l}28.45 \\
(6.05)\end{array}$ & & $\begin{array}{l}27.55 \\
(9.14)\end{array}$ & & & & $\begin{array}{l}27.20 \\
(8.50)\end{array}$ & & $\begin{array}{l}27.50 \\
(5.07)\end{array}$ & \\
\hline
\end{tabular}

ADCS-ADL = Alzheimer Disease Cooperative Study-Activities of Daily Living; CDR = Clinical Dementia Rating Scale; CDS = Cornell Depression Rating Scale; CIRS-s/c = Cumulative Illness Rating Scale severity/comorbidity; CMAI = Cohen-Mansfield Agitation Inventory; MMSE = Mini Mental State Examination (row score); NPI = Neuropsychiatric Inventory; QOL-C = Quality of Life Alzheimer Disease caregiver version; QOL-P = Quality of Life Alzheimer Disease patient version; WHODAS 2.0 = World Health Organization Disability Assessment Schedule 2.0.

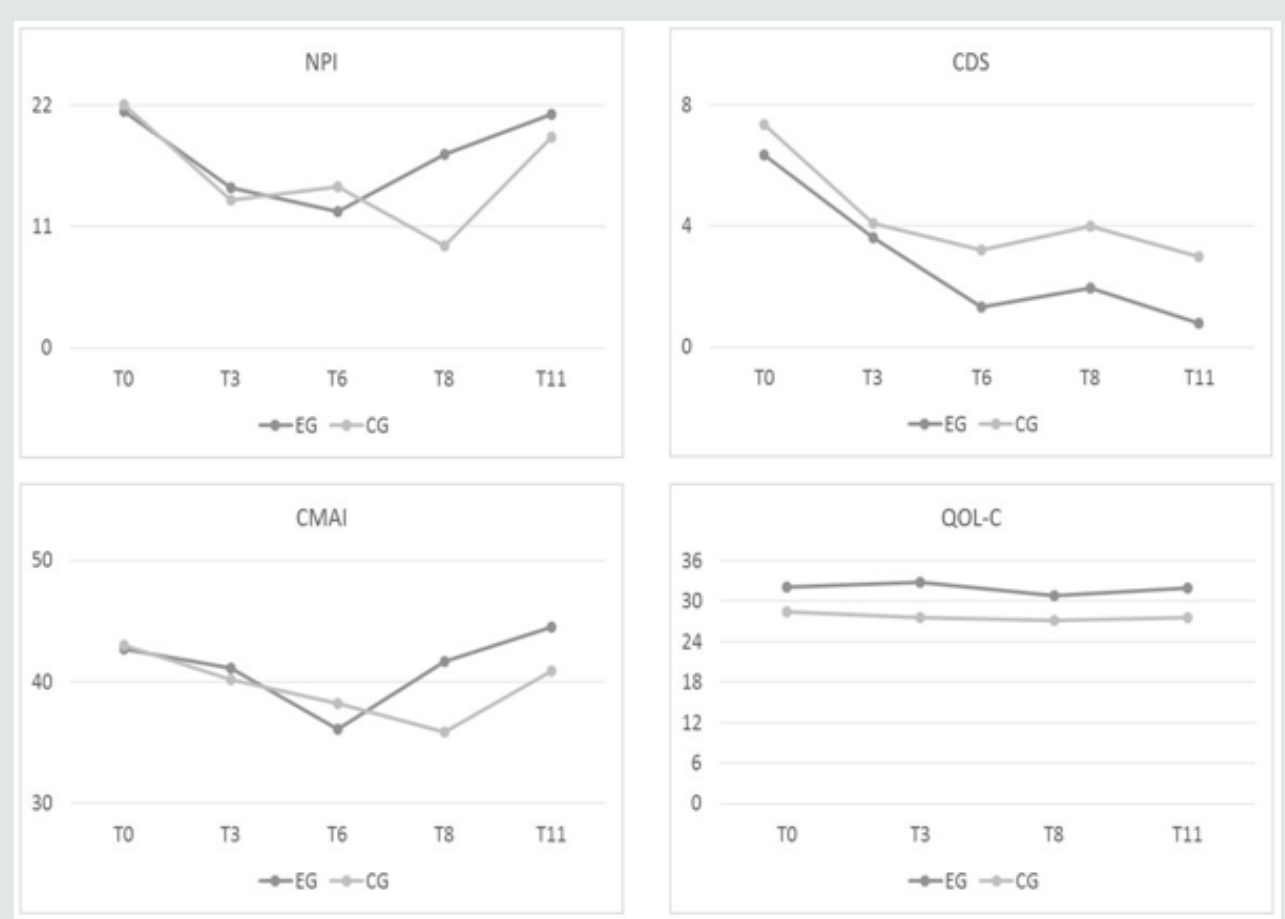

Figure 2: Results of the outcome measures detected with the Wilcoxon non-parametric statistic. The horizontal axis indicates month of the experimental phase $(\mathrm{T})$; the vertical axis indicates the scores on the measures.

NPI = Neuropsychiatric Inventory (range 0-144, the higher the score, the higher the level of neuropsychiatric disturbances); $\mathrm{CDS}=$ Cornell Depression Rating Scale (range 0-38, the higher the score, the higher the level of depression); $\mathrm{CMAI}=\mathrm{Cohen}-$ Mansfield Agitation Inventory (range 0-210, the higher the score, the higher the level of agitation); QOL-C = Quality of Life Alzheimer Disease caregiver version (range $0-48$, the higher the score, the better the QOL-AD).

Differences in outcome measures were observed within and between the CG and EG from T0 to T11, as follows. A significant difference on QOL-AD between samples emerged at T8. In particular, QOL-P $(\mathrm{p}<0.05)$ had a higher score in the EG $(32.86$ $\pm 9.87)$ than in the CG $(20.71 \pm 9.03)$ (Figure 1$)$. No differences between groups on the other outcome measures (NPI, CDS, CMAI, and QOL-C) were found from T0 to T11. No differences between
QOL-C and QOL-P were observed from T0 to T11. Table 2 displays differences within samples in dementia-related neuropsychiatric disturbance detected using the Wilcoxon non-parametric statistic. From $\mathrm{T} 3$ to $\mathrm{T} 11(\mathrm{p}=0.027)$ and from $\mathrm{T} 6$ to $\mathrm{T} 11(\mathrm{p}=0.007)$, the NPI score in the EG significantly increased. In the CG, the NPI score significantly increased from T0 to T8 $(p=0.050)$. Significant declines in depression (CDS) scores were found in the EG from T0 
to T3 $(p=0.054)$, and scores remained lower at T6 ( $p=0.001)$, T8 ( $\mathrm{p}=0.001)$, and T11 ( $\mathrm{p}=0.002)$. CDS scores also significantly decreased from T3 to T6 (p = 0.006), and the significant difference remained at T11 ( $p=0.022)$. There was also a significant decrease between T8 and T11 ( $p=0.046)$. For the CG, there was a significant decrease in CDS scores between T0 and T11 ( $p=0.011)$. Agitation (CMAI) scores fluctuated over the course of the study. A significant decrease was observed in the EG between T0 and T6 ( $p=0.005)$, and the T3 vs. T6 difference was also significant ( $p=0.017)$, whereas a significant increase occurred from T6 to T8 $(p=0.010)$, which remained at T11 ( $p=0.012$ for T6 vs. T11). A significant decrease was observed in the CG for T0 vs. T8 ( $p=0.015)$, part of which took place between $\mathrm{T} 6$ and $\mathrm{T} 8(\mathrm{p}=0.018)$. With respect to the QOL-AD, there are no differences in EG and CG on QOL-C, whereas a significant decrease was observed in the CG on QOL-P at T0 vs. T3 $(p=0.043)$ and T3 vs. T8 $(p=0.043)$. Figure 2 displays the graphs related to the results on the outcome measures. For CO, Figure 3 shows increases from pre to post MT in S2, S11, and S20, as well as for the measures taken at the corresponding times for the CG. (Figure 2) Both in the EG and in the CG the CO collection procedure appeared to be stressful. Some patients did not secrete enough saliva to measure CO. In the CG, results were obtained from five patients for S2, S11, and S20. The mean value in S2 increased from $6.678( \pm 0.434)$ to $7.318( \pm 0.238) \mu \mathrm{g} / \mathrm{l}(\mathrm{p}=0.077)$. In S11 there was a significant increase from $6.458( \pm 0.395)$ to $7.526( \pm 0.327)$ $\mu \mathrm{g} / \mathrm{l}(\mathrm{p}=0.041)$. There was also an increase from $7.420( \pm 1.076)$ to $7.956( \pm 0.571) \mu \mathrm{g} / \mathrm{l}(\mathrm{p}=0.340)$ in $\mathrm{S} 20$. In the $\mathrm{EG}$, results were obtained from nine patients for S2, S11, and S20. The mean value in S2 significantly increased from $6.359( \pm 1.045)$ to $6.990( \pm 1.021)$ $\mu \mathrm{g} / \mathrm{l}(\mathrm{p}=0.026)$. In S11 it slightly increased from $7.073( \pm 1.024)$ to $7.266( \pm 1.053) \mu \mathrm{g} / \mathrm{l}(\mathrm{p}=0.086)$. There was also an increase from $7.111( \pm 0.700)$ to $7.406( \pm 0.703) \mu \mathrm{g} / \mathrm{l}(\mathrm{p}=0.672)$ in $\mathrm{S} 20$.

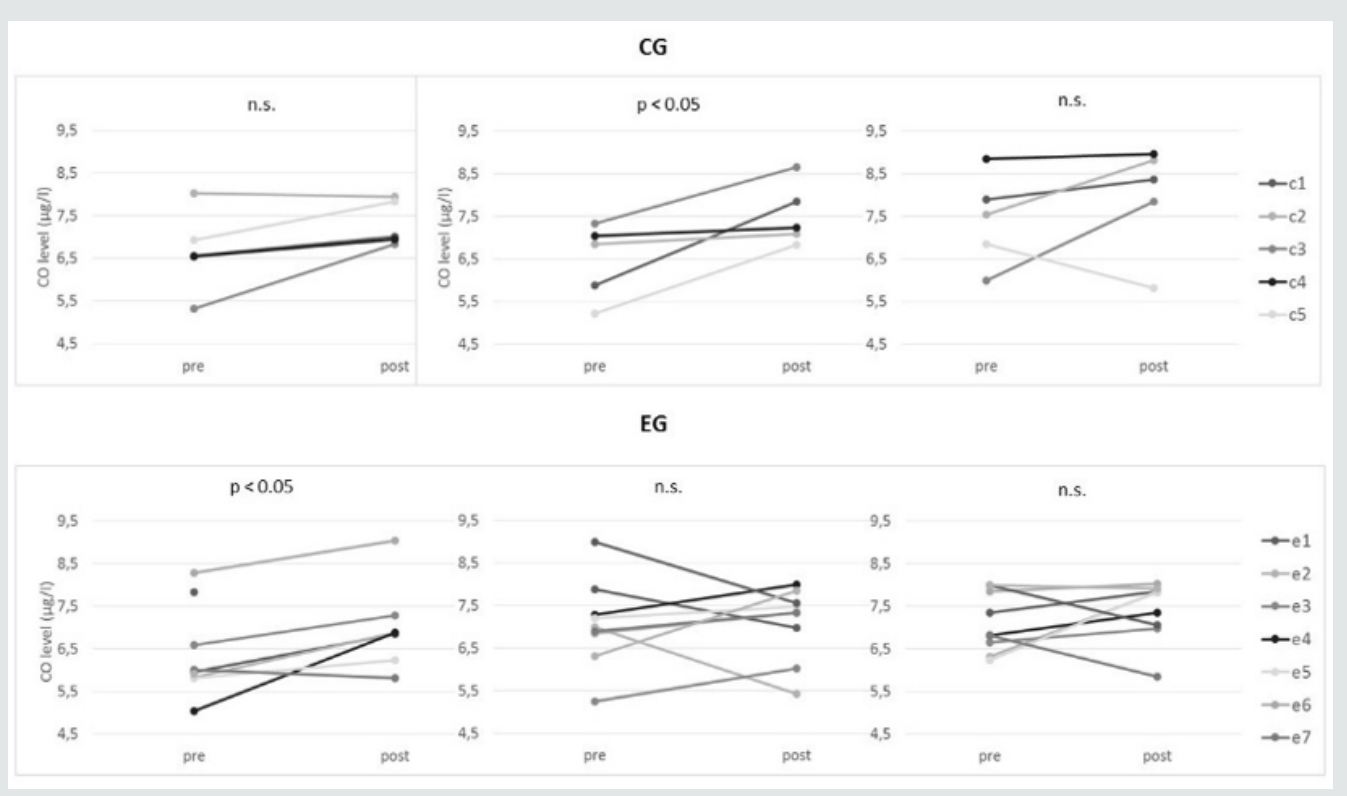

Figure 3: Pre- (MT intervention vs. control condition) and post-CO levels in CG and EG.

Diagrams on the left, CO collected during session time 2 (S2), diagrams in the middle are for S11, and diagrams on the right are for S20.

$\mathrm{c}=\mathrm{CG}$ (control group) patients; e = EG (experimental group) patients.

\section{Microanalysis of Mrs. R. a Patient of the Experimental Group}

Mrs. R. microanalysis is reported because she represents an emblematic clinical case for the age, the severity of the clinical condition and the sensorial impairment. This patient was a 91 yearold woman with moderate/severe vascular dementia (CDR $=2$ at T0, T8 and T11; MMSE = 14 at T0; MMSE = 17 at T3; MMSE $=17$ at T8; MMSE = 12 at T11). She had a first-grade education and worked as a housekeeper. She had a severe visual deficit, hypertensive heart disease, chronic obstructive bronchopneumopathy, controlled hypothyroidism, polyarthritis, and suffered from a hip fracture (CIRS-c $=5$ at T0, T8, and T11; CIRS-s $=1.86$ at T0, T8, and T11). All self-administered measures were provided by a formal caregiver (healthcare provider employed in the nursing home). At T0 and T3, she needed help in all basic and instrumental activities of daily living (ADCS-ADL = 5 at T0; ADCS-ADL = 3 at T3) except for the use of a fork or a spoon. At T6 and T8, she combed her hair, asking to listen to the radio, and commented on the news (ADCS-ADL $=11$ at T6). At T8 and T11, she reduced her activities (ADCS-ADL = 7 at T8; $\mathrm{ADCS}-\mathrm{ADL}=4$ at T11). The WHODAS 2.0 score remained the same throughout the study. Pharmacological treatment remained stable during the study. The CO before S2 was $8.28 \mu \mathrm{g} / \mathrm{l}$ and increased to $9.03 \mu \mathrm{g} / \mathrm{l}$ after the MT. At S11 CO was $6.85 \mu \mathrm{g} / \mathrm{l}$ before and 7.33 $\mu \mathrm{g} / \mathrm{l}$ after while at S20 they were $7.84 \mu \mathrm{g} / \mathrm{l}$ before and $8.02 \mu \mathrm{g} / \mathrm{l}$ 
after. On the NPI at baseline, Ms. R presented severe delusions, hallucinations, sleep disturbances, and sometimes depressive symptoms (NPI = 46 at $\mathrm{T} 0 ; \mathrm{NPI}=36$ at $\mathrm{T} 3 ; \mathrm{NPI}=11$ at $\mathrm{T} 6$; $\mathrm{NPI}=52$ at T8; NPI = 43 at T11).

She was verbally aggressive and engaged in repetitive actions $(\mathrm{CMAI}=50$ at $\mathrm{T} 0 ; \mathrm{CMAI}=38$ at $\mathrm{T} 3 ; \mathrm{CMAI}=38$ at $\mathrm{T} 6 ; \mathrm{CMAI}=59$ at T8; CMAI = 58 at T11). She expressed depressive symptoms during the study $(\mathrm{CDS}=17$ at $\mathrm{T} 0 ; \mathrm{CDS}=5$ at T3; $\mathrm{CDS}=0$ at T6; $\mathrm{CDS}=3$ at T8; CDS $=0$ at T11). She gave unreliable answers for the QOL items at T0 and T8, (QOL-P at T0 and T8 was inapplicable) and answers $(\mathrm{QOL}-\mathrm{P}=28$ at T3; ADCS-ADL $=31$ at T11) comparable to those given by the caregiver ( $\mathrm{QOL}-\mathrm{C}=30$ at T0; $\mathrm{QOL}-\mathrm{C}=32$ at T3; $\mathrm{QOL}-\mathrm{C}$ $=33$ at T8; QOL-C = 28 at T11) at T3 and T11. Sessions graphs evidenced a progressive increase in involvement in the MT (eye contact, language, and spontaneous movement). (Figure 4) The music therapist reported that Mrs. R reveals receptive participation in the MT by listening, marking the beat, and playing the maracas. Her behavioral response in the sessions was very positive, and she had her identity and self-worth confirmed by the experience. She was also emotionally affected by the songs, showing interest in the therapist (e.g., by searching for a touch). Based on the video analysis (Supplemental Material), it was concluded that Mrs. R. benefited from the MT as showed in Tables 3 \& 4 .

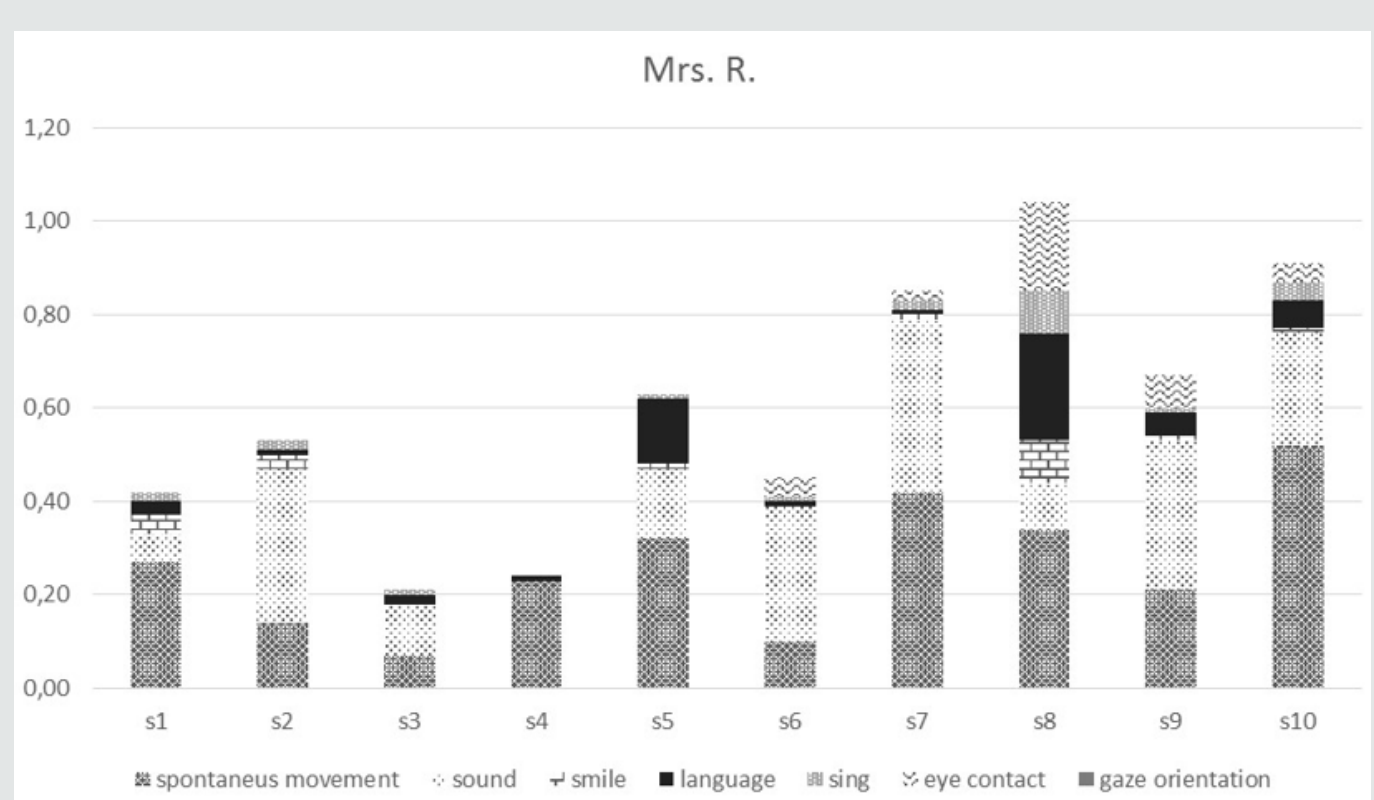

Figure 4: Mrs. R.'s salient behaviors (see sorting bar by value) computed as a proportion of their duration in seconds. $S$ indicates session time (s1, etc.).

Table 3: Outcomes from the MT analysis.

\begin{tabular}{|c|c|}
\hline $\begin{array}{l}\text { Mrs. R.'s outcomes from the MT. } \\
\text { (See also Table 1, column C of the Supplemental Material) }\end{array}$ & $\begin{array}{l}\text { Examples of Analyst's observation of meaningful events of the MT sessions' video. } \\
\text { (See also Table 1, column A of the Supplemental Material). }\end{array}$ \\
\hline She was engaged in the songs. & $\begin{array}{l}\text { Mrs. R. plays the maracas, keeping the rhythm of the music. She moves her head and } \\
\text { shoulders with a pleasant and smiling expression. Towards the end of the instrumental } \\
\text { part, she slows down the rhythm (Clip 2, sequence 5). }\end{array}$ \\
\hline She smiles. & $\begin{array}{l}\text { Mrs. R. [...] makes a gesture with the head, smiles happily and takes part in the group's } \\
\text { applause (Clip 5, sequence 3). }\end{array}$ \\
\hline She actively participated. & Mrs. R. claps her hands and smiles (Clip 1, sequence 4). \\
\hline She responded relevantly. & Mrs. R. plays the maracas, keeping the rhythm of the music (Clip 2, sequence 5). \\
\hline She took the initiative. & Mrs. R. searches physical contact with Therapist's arms (Clip 1, sequence 4). \\
\hline $\begin{array}{l}\text { She understood that the therapist was offering contact } \\
\text { and was aware of and appreciated the contact. }\end{array}$ & At the touch of Therapist's, Mrs. R. starts to play the instrument (Clip 2, sequence 3). \\
\hline She was able to express pleasure and contentment. & $\begin{array}{c}\text { During the welcome song, she nods several times, smiles and moves her lips (Clip 1, } \\
\text { sequence 3). }\end{array}$ \\
\hline She engages in a dialogue with the therapist. & $\begin{array}{l}\text { The therapist plays the guitar and exclaims “Good, Mrs. R.!". Mrs. R. plays xylophone keys } \\
\text { while listening to the therapist's words. He repeats “Good!" and she plays her instrument } \\
\text { with a pleased expression. }\end{array}$ \\
\hline She was linguistically and verbally stimulated. & Mrs. R. says, “I am the oldest! Eh!” (Clip 5, sequence 4). \\
\hline
\end{tabular}

In the column on the right, clips and sequences refer to the video consisting of the most salient moments of the therapy of Mrs. R. created by the therapist (Supplemental Material). 
Table 4: Videoclip analysis related to Mrs. R. Analyst = Trained student of psychology; Mrs. R. = Clinical case; MT = Music Therapy; Therapist $=$ Music Therapist (Francesco Delicati).

\begin{tabular}{|c|c|c|}
\hline $\begin{array}{l}\text { A - Analyst's observation of meaningful events of the } \\
\text { MT sessions' video. }\end{array}$ & $\begin{array}{c}\text { B - Therapist's interpretation of events } \\
\text { reported in column A. (The MT thinks } \\
\text { about that...) }\end{array}$ & $\begin{array}{l}\text { C - Therapist's reflection on the Mrs. } \\
\text { R.'s response to the MT reported in } \\
\text { columns A and B. }\end{array}$ \\
\hline \multicolumn{3}{|c|}{ Clip 1} \\
\hline \multicolumn{3}{|c|}{ Sequence 1} \\
\hline $\begin{array}{l}\text { The Therapist knells down behind a senior woman of } \\
\text { the group in a wheelchair. He sings a musical motif of } \\
\text { welcome and plays the guitar. He concludes with a positive } \\
\text { expression and applause. Mrs. R. is sitting next to the old } \\
\text { woman in a wheelchair. She packs away a paper towel in her } \\
\text { waistcoat's pocket and takes part to the applause. }\end{array}$ & $\begin{array}{l}\text { Despite the blindness, Mrs. R. seems to } \\
\text { be present in the situation: during the } \\
\text { applause, she also joins the other people } \\
\text { clapping her hands as an automatic } \\
\text { response. }\end{array}$ & $\begin{array}{l}\text { Mrs. R. shows an active involvement } \\
\text { (claps her hands). }\end{array}$ \\
\hline \multicolumn{3}{|c|}{ Sequence 2} \\
\hline $\begin{array}{l}\text { Mrs. R. keeps clapping. The Therapist addresses her asking } \\
\text { her name to the group. He crouches in front of her and } \\
\text { touches her hand softly repeating her name (an animator } \\
\text { says her name). Mrs. R. responses at the touch of the hand } \\
\text { slightly moving hands towards Therapist. She repeats } \\
\text { her name and smiles.Mrs. R. responses at the touch of the } \\
\text { hand, moving towards Therapist. She repeats her name and } \\
\text { smiles. }\end{array}$ & $\begin{array}{l}\text { Therapist involves the group towards Mrs. } \\
\text { R. Aware of her blindness he establishes a } \\
\text { contact through a twofold communication: } \\
\text { verbal (repeating her name) and tactile } \\
\text { (touching her hand). Mrs. R seems } \\
\text { pleasantly surprised by the Therapist's } \\
\text { contact. She seems to search for the contact } \\
\text { with Therapist hand who plays the guitar. } \\
\text { She appears pleased and happy to receive } \\
\text { interest from others. }\end{array}$ & $\begin{array}{l}\text { Mrs. R. shows interest in the Therapist. } \\
\text { She takes the initiative to contact } \\
\text { him. She expresses intentionality, } \\
\text { responsiveness and a positive state of } \\
\text { mind. }\end{array}$ \\
\hline \multicolumn{3}{|c|}{ Sequence 3} \\
\hline $\begin{array}{l}\text { The Therapist welcomes Mrs. R. involving the rest of } \\
\text { the group, orienting gaze and the face. He alternates } \\
\text { gesticulation (arm and right hand) to playing guitar. } \\
\text { He keeps the time of the song. He concludes by saying } \\
\text { "Welcome R.!" clapping his hands and involving the group. } \\
\text { Mrs. R. claps her hands and smiles. She brings her hand } \\
\text { near the face and caresses herself hands together. During } \\
\text { the welcome song, she nods several times, smiles and moves } \\
\text { her lips. }\end{array}$ & $\begin{array}{l}\text { The therapist looks and indicates Mrs. R. He } \\
\text { wants to focus group's attention towards } \\
\text { her. Mrs. R. seems focused on welcome } \\
\text { song listening. She expresses pleasure and } \\
\text { wonders with body language (e.g., slightly } \\
\text { open mouth, the nodding). She seems to feel } \\
\text { recognized as a special person. She seems to } \\
\text { participate using lips movements... probably } \\
\text { a hint of singing. }\end{array}$ & $\begin{array}{l}\text { Mrs. R. listens and is involved with her } \\
\text { body. She participates in the experience. }\end{array}$ \\
\hline \multicolumn{3}{|c|}{ Sequence 4} \\
\hline $\begin{array}{l}\text { The Therapist gets up and betakes oneself towards a } \\
\text { participant, asking for Mrs. R.'s name to the group. A group } \\
\text { member touches Mrs. R. She rolls over her nearby and } \\
\text { smiles. She searches physical contact with Therapist's arms, } \\
\text { but she touches the guitar. }\end{array}$ & $\begin{array}{l}\text { The Therapist is too fast in his going from } \\
\text { one group member to another. Mrs. R. } \\
\text { requires more time. Probably she could be } \\
\text { express more emotions and could receive } \\
\text { more sense of recognition if more time was } \\
\text { given. However, this mistake is compensated } \\
\text { by the contact with her neighbor, who } \\
\text { empathized with her. In fact, she expresses } \\
\text { a need of contact with Therapist, searching } \\
\text { his hands. Mrs. R. is present to the situation. } \\
\text { She seems to perceive her person as part of } \\
\text { the group. She seems very happy while claps } \\
\text { her hands and smiles. }\end{array}$ & $\begin{array}{l}\text { Mrs. R. shows a receptive involvement } \\
\text { (e.g., she orients herself towards } \\
\text { Therapist) and she takes the initiative } \\
\text { searching for a contact. }\end{array}$ \\
\hline \multicolumn{3}{|c|}{ Clip 2} \\
\hline \multicolumn{3}{|c|}{ Sequence 1} \\
\hline & $\begin{array}{l}\text { The Therapist chose the song "Rosamunda" } \\
\text { to gratify, enhance and involve Mrs. R. Mrs. } \\
\text { R. seems much focused on listening. I think } \\
\text { she recognizes herself in the phrase "you } \\
\text { are the love for me" (she nods). She keeps } \\
\text { nodding and has a prolonged smile an } \\
\text { aspect that gives me the idea of recognizing } \\
\text { herself in a familiar song. She expresses } \\
\text { pleasure probably because familiarity } \\
\text { induces feelings of security. Using the } \\
\text { request to complete the musical phrase, } \\
\text { the Therapist uses the question/answer } \\
\text { technique to stimulate the participation. }\end{array}$ & $\begin{array}{l}\text { Mrs. R. plays the maracas, listens and } \\
\text { recognizes the song. }\end{array}$ \\
\hline
\end{tabular}


Sequence 2

The Therapist is kneeling in front of four group members and sings the opening word of the "Rosamunda"'s song. He plays the accordion with the left hand and emphasizes the musical syllables. At the same time, he moves the right hand toward participants and chants the syllables of the first part of the song's phrase. A participant completes the first musical phrase of the song. Mrs. R. mentions moving the maracas. When the noun is pronounced (Rosamunda sound similar to her name), she starts to listen. When the participant completes the first verse of the song, Mrs. R. nods, moves her head and smiles. The Therapist's gaze is oriented toward the group. He gesticulates with the right hand while he plays the guitar with the left hand. He signs with the participants and passes the musical phrase. He points his chest and indicates his heart when he sings "love" and "for you." Mrs. R. holds maracas, listens, nods slightly moves her head and mentions some words of the lyric.

Singing, "all my love is for you" the Therapist brings his right hand close to Mrs. R.'s hand, and he repeats the musical phrase to her. At the touch of Therapist's, Mrs. R. starts to play the instrument.
The Therapist involves the group to enhance Mrs. R. and to stimulate her participation. In addition, the musical phrase facilitates the group's attention for her. Mrs. R. seems actively listening. In fact, she holds maracas, nods her head and hints to sing.
Mrs. R. is so stimulated by the familiar song, that she tries to sing some words of the text.

\section{Sequence 3}

The Therapist concludes its stimulation activity on Mrs. R. With his actions, he communicates that she is the center of the attention and that she is the protagonist of the song. The touch of her hand in association with the musical phrase is evidence of this.

\section{Sequence 4}

The Therapist starts again to sing the song. He articulates the musical part, playing the accordion. Sometimes he stops the musical part and continues only with the voice. He moves the right hand in towards the group. Mrs. R. doesn't play her instrument in time with music and, at the end of the song, she slows down the shaking of the maracas and she seems to sing the word "Rosamunda," according to the Therapist's voice.
The Therapist plays the accordion and stops to put in evidence the words of the song. Mrs. R. constantly participates in the activity of singing and playing the instrument with pleasure. The slowdown in playing the maracas seems an attempt to keep time. Although she sings a unique word ("Rosamunda"), she reveals active participation.

Sequence 5

The Therapist leaves the song and starts to play the accordion, watching Mrs. R. that shaking the maracas. Le rest of group start playing instruments, trying to keep the rhythm proposed by Therapist. Mrs. R. plays the maracas in keeping the rhythm of the music. She moves her head and shoulders with a pleasant and smiling expression. Towards the end of the instrumental part, she slows down the rhythm.
The Therapist intensifies the energy playing accordion after have obtained the involvement of the group. Playing the accordion, he follows the rhythm proposed by Mrs.'s maracas, a signal of listening and attention. Mrs. R. seems present and active in the experience as her body movement reveals. She plays maracas for a long time and she smiles most of the time.
Because of Therapist's contact, Mrs. R. plays the maracas independently by her ability to keep time.
Mrs. R. participates. She plays the maracas, tries to keep time and sings during the song.

\section{Clip 3}

\section{Sequence 1}

The Therapist, sitting among the elderly, plays the accordion and sings "Bella Ciao." He listens Mrs. R. Mrs. R. is holding maracas (she doesn't play it) oriented towards the therapist and the accordion (source of the sound). During the melodic rhythm part of the sing, she begins to move the head.

Mrs. R. listens, and when the therapist plays the melodic rhythm part, she starts to move the head.
Despite the blindness, Mrs. R. and Therapist establish a relationship using non-verbal deliveries, complicity,

help, and support of the group. The relationship is implemented firstly by the use of a familiar song and secondarily by physical contact (hands). Despite sometimes the rhythm of maracas differ from the accordion; the Therapist and

Mrs. R. go hand in hand in the same relationship through singing and playing.

\section{Sequence 2}

The Therapist plays the accordion with a detached articulation, especially in the rhythmic part. While the other elders keep the rhythm playing their instruments, Mrs. R. moves her head to the rhythm of the song.
The Therapist's mode of playing the accordion (detached) seems to give energy to the group. Mrs. R. seems to know the song very well. She follows the rhythm

continuously with head's movement, especially during the melodic-rhythmic part. The rhythm is the most important factor in her musical fruition.
Mrs. R. shows receptive participation, and she engages in a dialogue with the Therapist.
Mrs. R. responds to the stimulation moving her head. She shows active participation and seems inside the rhythm of the song. 


\section{Sequence 3}

The Therapist continues to play. He directs his gaze and listens to an old woman in a wheelchair, at the left of Mrs. R. He respects and amplifies the old woman's mode of playing (detached) tambourine. Mrs. R. continues to mark the rhythm. She moves the head and the upper part of the shoulders. At the same time, she sings of the refrain.
The Therapist continues to play with a detached articulation, reflecting the movement of the old woman on the left of Mrs. R. The tambourine's rhythm simplify Mrs. R.'s participation.
Mrs. R. shows active participation with the involvement of the body's movements and by singing.

\section{Sequence 4}

The Therapist continues to play with the technique of detached and moves his gaze and his attention to Mrs. R. She moves her head imperceptibly, and the upper part of the body, at the rhythm of the music. Mrs. R. continues to mark the rhythm of the song at the body level. Although she is sitting, the head's movement involves the upper part of the body.
The Therapist controls what happens inside the group. His highlighting, resuming and emphasizing the musical modalities of each person allows to enhance what each person does and to put these activities at the service of the group. Even if Mrs. R. does not show changes in her being in the experience, she maintains her modality and this "going to the step" and continuing in the same activity seems very pleasant for her. Mrs. R. seems to "capture" the rhythm of the song, giving a confirm of the importance of the rhythm together with the knowledge and familiarity of the song.
Mrs. R. engages a dialogue with the therapist and the group. She shows active participation marking the beat, phrasing the melodies and singing.

\section{Clip 4}

\section{Sequence 1}

The Therapist takes up his guitar and kneels in front of Mrs. R. She plays the xylophone, beating with energy with a wand on the wooden keys. The Therapist plays the guitar accompanying and supporting the motif created by Mrs. R.'s beating on the xylophone.
Mrs. R. is active and determinate. She plays the xylophone producing a casual melody with decision and energy. The Therapist carries out a task of support to Mrs. R. activity. In a Gestaltic manner, Mrs. R.'s melody is in the figure, while the sound of the guitar that remains in the background
Mrs. R. plays a random rhythmic-melodic motif on the xylophone and takes the initiative. She is actively involved.

\section{Sequence 2}

The therapist plays the guitar and exclaims “Good, R.!”. Mrs. R. plays xylophone's keys listening to the therapist's words. He repeats “Good!". Mrs. R. plays her instrument with a pleased expression.
The Therapist seems to be satisfied to interact with Mrs. R. His's words carry support and confirm Mrs. R.'s identity. Mrs. R. seems very happy for Therapist's words. She responses with a pleased expression maintaining her musical activity.
Mrs. R. is immersed in the percussive action and continues with constancy and commitment, without stopping. She was not distracted from Therapist's words an aspect that denotes mastery and security in this activity.

\section{Sequence 3}

The Therapist knells down in front of Mrs. R. and continues to play the guitar, accompanying her. Mrs. R. plays the xylophone, while another old woman, at the left of Mrs. R., plays the tambourine on the table of her wheelchair with a drumstick. Meanwhile, the Therapist turns his gaze on towards other women who seem not to respond to music.
Mrs. R. and the Therapist, along with another woman, continue in their collective performance. The Therapist seems to look around to monitor what is happening and if anything changes.
Mrs. R. remains immersed in the percussive action with constancy. She is involved and not appears tired.

\section{Sequence 4}

The Therapist shortly stops playing the guitar. He takes a drumstick and begins to hit a vertical drum on his left. While Mrs. R. plays the xylophone, the Therapist restarts to play the guitar and turns his gaze toward a senior woman on his left. He alternatively plays the guitar and gives two bangs on the drum. The senior woman stays still and looks away. She is observed by the senior woman, who plays the drum.
The Therapist, continuing to play, tries to stimulate, with his gaze and the drum, a senior woman who stays still and distracted.
Mrs. R. is actively involved. She continues to play the xylophone. 
Sequence 5 from 3.21

The Therapist plays the guitar and the drum. He still looks at the senior woman who, being watched, looks at him pleased. The senior woman who plays the drum is sited next to Mrs. R. The woman mimics the Therapist playing also another drum and looks pleased the Therapist. He smiles and nods at her.
The Therapist tries to stimulate a senior woman who seems to notice the Therapist's interest. The Therapist seems surprised by the action of the woman who plays the tambourine and smiles with complicity. The Therapist restores a positive assent continuing to play and nodding. Mrs.

R. continues to play the xylophone. She appears involved and happy.
Mrs. R. shows active participation with an unusual instrument (the xylophone). She keeps a fairly constant rhythm and probably is not aware of the melody that composes on the xylophone. It is positive that she does not stop on a single key: she beats and runs on more keys of the xylophone. Perhaps she is not aware that is in course an improvisation, but she keeps playing together at the threesome. She plays the xylophone energetically receiving a response in terms of vibration. The vibration involves her body, and above all the arm that beats. It is positive, for his image's confirmation, to feel the sound and the vibration product of his action.

\section{Clip 5}

Sequence 1

The Therapist kneels in front of the group that is disposed of as a circle. He plays the accordion and sings with emphasis the text of the song "Calabresella," directing the bust and the gaze towards the women. He plays the instrument dilated

with his left hand and uses the other hand to scan the rhythm to involve the group. The senior women hold hands and move in time to the music; some of them sing. Mrs. R. is involved and sings staying in times. In particular, she moves the left arm connected to a senior woman particularly active both in singing and in movement.
Mrs. R. is well integrated into this collective action. Her face expresses concentration. She sings the song staying in time and seems to "let himself be moved" by the action of the women that held her hands.
The person is involved in the collective action, participating with the movement and singing.

\section{Sequence 2}

The Therapist interrupts the song and plays the instrumental part of the song with the accordion. Some women start to move to the rhythm of music and to sing. Mrs. R. moves spontaneously to the rhythm of the music, involving the body: the head in particular.
Mrs. R. continues to follow the behavior of attention and participation with a slight increase in the movement. She tries pleasure from what she is doing. Thanks to her hand content, she seems friendly: a positive aspect considering the tendency to stiffen of the blind persons.

\section{Sequence 3}

The Therapist ends the song playing with the left hand while makes a final gesture with his right arm and exclaims "olé."The group starts applause, and the Therapist joins. Mrs. R. immediately after the musical closing and the ole makes a gesture with the head, smiles happily and takes part in the group's applause. The Therapist, continuing to applaud, exclaims "Good! Good". Some women reply "Good!."
The Therapist concludes with a gesture and an exclamation that are in line with the energetic and emphatic way of playing. Mrs. R. seems to be satisfied, smiles happily, and seems to give herself up to this state of mind. She also demonstrates to warn the musical closing of the piece with the head's gesture. The Therapist reinforces with the praises, the esteem and the positive image of the elderly, including Mrs. R. The group repays. General satisfaction is present.
Mrs. R. is fully integrated into the collective motor action and seems happy.

\section{Sequence 4}

The Therapist rises from the ground,and Mrs. R. says, "I am the oldest! Eh." The Therapist replies asking, "Who is the oldest?" Mrs. R. answers "Me!" in a high pitch The Therapist says "My God! Let's hear it to the oldest!" He starts to applaud and touches Mrs. R.'s shoulder. Some members of the group take part in the applause. Mrs. Ro. repeats, "I am the oldest!" The Therapist, moving away from Mrs. R., smiles and says "An applause to the oldest!" Mrs. R. concludes laughing with "Eh, I have more years!"
Mrs. R. is very happy to make it clear and state that she plays an important role: she is the woman who has more years than all the people present. The Therapist plays with surprise and amused by Mrs. R.'s exclamation. He answers her tone and asks for confirmation of who spoke. Mrs. R. replies affirmatively in a sharp tone and seems very happy. Mrs. R. looks very amused. She and the Therapist laugh
The patient understands the musical closing of the song. She is very happy and content.
Mrs. R. exposes herself, expressing what she considers a note of merit (having more years). She takes the initiative, trusts the situation and people and communicates verbally with the Therapist. The Therapist and Mrs. R. are involved in a pleasure dialogue in which play, emotion, and joy are present. The music therapy gives pleasure, increases the wellbeing, and reinforces Mrs. R.'s identity and self-esteem thanks to the "us" of the peer group. 


\section{Discussion}

Several studies have suggested the possibility of innovative paradigms able to capture MT effects in dementia $[5,9,15]$. The present study aimed to demonstrate the usefulness of our biopsychosocial paradigm to explore if MT is useful. To reach this aim, we used outcome measures such as the NPI, CMAI, CDS, and QOL-AD to assess the impact of music therapy on behavioral disturbances and quality of life in persons with moderate/ severe dementia living in a nursing home. Biological markers and relational aspects of behavior were also assessed using salivary cortisol analysis and Microanalysis, respectively. At the same time, health status was monitored throughout the study with the C-Int, CDR, CIRS, MMSE, WHODAS 2.0, and ADCS-ADL. The biopsychosocial paradigm seems capable of capturing MT effects on the degenerative and progressive process of ingravescent health conditions that characterize dementia. In fact, as expected (second prediction), a significant decrease in quality of life (QOL-P score) was observed for the CG but not for the EG [15], even though health status worsened in the EG. Moreover, the EG manifested improvement in functional capacity, showing significant increases in average ADCS-ADL scores. However, the prediction that the EG would obtain NPI, CMAI, and CDS scores lower than the CG (i.e., manifest a lower level of behavioral and psychological symptoms of dementia) was disconfirmed, although within the EG there was a nonsignificant trend toward decreased behavioral disturbances from $\mathrm{T} 0$ to $\mathrm{T} 11$, partially confirming previous studies [2,9,22]. The third prediction - that EG participants would show decreased signs of stress, as indicated by salivary cortisol (CO) levels-was not confirmed. Our results showed no significant difference between EG and CG on CO; in addition, a significant CO increase was present in S2 on EG and in S11 on CG. However, patients e2, e6, and e8, belonging to the EG, showed a reduced CO at S11. Literature is controversial about the effect of MT. Although Evans et al. [49] and Suzuki et al. [24] found a diminished secretion of cortisol correlated with positive psychological well-being, respectively in aging people the first and people with dementia the last; conversely, Takahashi and Matsushita [50] found no significant effect among person with moderate and severe dementia after MT.

The fourth prediction - that social skills and participation would be enhanced by MT-was supported. Through the Microanalysis, it was possible to demonstrate that salient behaviors (e.g., when the patient joins in singing, plays, smiles, makes appropriate eye contact during interaction, spontaneously moves their body, etc.) were enhanced, providing evidence that MT is effective for enriching relational and communicative abilities in those with moderate/severe dementia, as Raglio et al. [2] found. Despite her CO increasing (Figure 3), Ms. R (e6) was engaged with positive emotions with the music therapist and participated actively in the group activities. The fact that $\mathrm{CO}$ collection was perceived by the patients as a stressful procedure might explain the fact that $\mathrm{CO}$ increased in both the EG and the CG. Furthermore, the increase in CO after MT may be indicative of beneficial stress (eustress) and not negative stress (distress) [51], that is a consequence of patient's activation following the biopsychosocial intervention. In fact, as Chanda and Levitin argue [14], active MT intervention (direct interactions to stimulate participants) could increase cortisol.

\section{Limitations of the Study}

The small sample size, the heterogeneity of the subjects, and the presence of formal caregivers reduced the possibility of generalizing the results. Futures studies are required to confirm the utility of our paradigm. The majority of the quantitative outcomes (Table 2) are not statistically significant. We know that statistical significance in psychosocial studies is a highly controversial issue. In dementia studies, statistical comparison between groups (experimental and control) could be compromised by a twofold difficulty [52]: the short-term and non-permanent changes in the expression of signs and symptoms of a single individual in the same day; 2) the variability of the expression of signs and symptoms among person with the same diagnosis. Nevertheless, in our study, notable changes in individual measures was observed (although not statistically significant) that might be considered significant from a clinical point of view. Although a clinical analysis of our findings is indubitably interesting, it is beyond the aim of the present study. In summary, the results suggested that the paradigm is effective in demonstrating MT effects in patients with moderate/severe dementia. Active MT is effective in preserving a higher quality of life in institutionalized older adults with moderate/severe dementia. According to demographic projections, the oldest old with dementia will increase in the coming years, and it will be important to have means available to reliably detect the effects of bioecopsychosocial [53] (usually called non-pharmacological) interventions designed to increase the quality of life in those with dementia.

\section{Acknowledgement}

This study was co-funded by Regione Umbria, Ricerca Sanitaria Finalizzata (MUSICT14; E17903P4), and by "Associational Malattia Alzheimer e Telefono Alzheimer Umbria” (A.M.A.T.A. Umbria). The authors would like to thank: Catia Passeri and Maria Grazia Marcacci (nursing homes' social workers), the nursing homes' healthcare assistants, and the students of the Department of Philosophy, Social \& Human Sciences and Education, who supported the study.

\section{References}

1. Koger SM, Brotons M (2003) Music therapy for dementia symptoms. Cochrane Database Syst Rev (2): Cd001121.

2. Raglio A, Bellelli G, Traficante D, Gianotti M, Ubezio MC, et al. (2008) Efficacy of music therapy in the treatment of behavioral and psychiatric symptoms of dementia. Alzheimer Dis Assoc Disord 22(2): 158-162.

3. Raglio A, Bellelli G, Mazzola P, Bellandi D, Giovagnoli AR, et al. (2012) Music, music therapy and dementia: A review of literature and the recommendations of the Italian Psychogeriatric Association. Maturitas 72(4): 305-310 
4. Snowden M, Sato K, Roy Byrne P (2003) Assessment and treatment of nursing home residents with depression or behavioral symptoms associated with dementia: a review of the literature. J Am Geriatr Soc 51(9): 1305-1317.

5. Vink AC, Birks JS, Bruinsma MS, Scholten RJ (2004) Music therapy for people with dementia. Cochrane Database Syst Rev (3): CD003477.

6. Pollack NJ, Namazi KH (1992) The Effect of Music Participation on the Social Behavior of Alzheimer's Disease Patients1. J Music Ther 29(1): 54-67.

7. Cuddy LL, Duffin J (2005) Music, memory, and Alzheimer's disease: is music recognition spared in dementia, and how can it be assessed? Med Hypotheses 64(2): 229-235.

8. Verghese J, Lipton RB, Katz MJ, Hall CB, Derby CA, Kuslansky G, et al. (2003) Leisure activities and the risk of dementia in the elderly. $\mathrm{N}$ Engl Med 348(25): 2508-2516.

9. McDermott O, Crellin N, Ridder HM, Orrell M (2013) Music therapy in dementia: a narrative synthesis systematic review. Int J Geriatr Psychiatry 28(8): 781-794.

10. Edwards J (2005) Possibilities and problems for evidence-based practice in music therapy. Art Psychother 32(4): 293-301.

11. Haynes RB (2002) What kind of evidence is it that Evidence-Based Medicine advocates want health care providers and consumers to pay attention to? BMC Health Serv Res 2(1): 3.

12. O'Callaghan C (2015) Music therapy. In: Cherny NI, Fallon M, Kaasa S, Portenoy RK, Currow D, et al. Oxford Textbook of Palliative Medicine. NY: Oxford University Press, New York, pp. 184-190.

13. Vink AC, Bruinsma MS (2003) Evidence Based Music Therapy. Music Therapy Today 4(5): 1-26.

14. Chanda ML, Levitin DJ (2013) The neurochemistry of music. Trends Cogn Sci 17(4): 179-193.

15. Solé C, Mercadal Brotons M, Galati A, De Castro M (2014) Effects of Group Music Therapy on Quality of Life, Affect, and Participation in People with Varying Levels of Dementia. J Music Ther 51(1): 103-125.

16. Samson S, Clément S, Narme P, Schiaratura L, Ehrlé N (2015) Efficacy of musical interventions in dementia: methodological requirements of nonpharmacological trials. Ann N Y Acad Sci 1337: 249-255.

17. Rubenstein LZ (1995) An Overview of Comprehensive Geriatric Assessment: Rationale, History, Programs Models, Basic Components. In: Rubenstein LZ, Wieland D, Bernabei R, editors. Geriatric Assessment Technology: The State of the Art. NY: Oxford University Press, New York, p 1-9.

18. WHO (World Health Organization) (2001) ICF: International Classification of Functioning, Disability and Health? Geneva.

19. Pigliautile M, Tiberio L, Mecocci P, Federici S (2018) The Geriatrician. In: Federici S, Scherer MJ, editors. Assistive Technology Assessment Handbook. $2^{\text {nd }}$ ed. FL: CRC Press, Boca Rato,n pp. 265-299.

20. Scherer MJ, Federici S, Tiberio L, Pigliautile M, Corradi F, et al. (2012) ICF core set for Matching Older Adults with Dementia and Technology. Ageing Int 37(4): 414-440.

21. White H (2013) The Use of Mixed Methods in Randomized Control Trials. In: Mertens DM, Hesse-Biber S, editors. Mixed methods and credibility of evidence in evaluation New Directions for Evaluation: Wiley, p. 61-73.

22. Ueda T, Suzukamo Y, Sato M, Izumi SI (2013) Effects of music therapy on behavioral and psychological symptoms of dementia: a systematic review and meta-analysis. Ageing Res Rev 12(2): 628-641.

23. Logsdon RG, McCurry SM, Teri L (2007) Evidence-Based Interventions to Improve Quality of Life for Individuals with Dementia. Alzheimer's care today 8(4): 309-318.

24. Suzuki M, Kanamori M, Watanabe M, Nagasawa S, Kojima E, et al. (2004)
Behavioral and endocrinological evaluation of music therapy for elderly patients with dementia. Nurs Health Sci 6(1): 11-18.

25. Clair AA, Bernstein B (1990) A Preliminary Study of Music Therapy Programming for Severely Regressed Persons With Alzheimer's-Type Dementia. J Appl Gerontol 9(3): 299-311.

26. APA (American Psychiatric Association) (2000). Diagnostic and Statistical Manual of Mental Disorders: DSM-IV-TR ${ }^{\circledR}$. $\left(4^{\text {th }}\right.$ edn $)$; Arlington, VA.

27. Morris JC (1993) The Clinical Dementia Rating (CDR): current version and scoring rules. Neurology 43(11): 2412-2414

28. Folstein MF, Folstein SE, McHugh PR (1657) Mini-mental state: A practical method for grading the cognitive state of patients for the clinician. J Psychiatr Res 12(3): 89-98.

29. Delicati F (2010) The heart does not forget: Music therapy and memories in Alzheimer's patients, Assisi, IT: Cittadella.

30. Cremaschi Trovesi G (2007) Music therapy: Art of communication. Roma, IT, Magi.

31. Scardovelli M (1992) Il dialogosonoro. Bologna, IT, Cappelli.

32. Scardovelli M (2007) Musica e transformational. Roma, IT, Borla

33. Raglio A, Filippi S, Bellandi D, Stramba-Badiale M (2014) Global music approach to persons with dementia: evidence and practice. Clin Interv Aging 9: 1669-1676.

34. Parmelee PA, Thuras PD, Katz IR, Lawton MP (1995) Validation of the Cumulative Illness Rating Scale in a geriatric residential population. J Am Geriatr Soc 43(2): 130-137.

35. Galasko D, Bennett D, Sano M, Ernesto C, Thomas R, et al. (1997) An inventory to assess activities of daily living for clinical trials in Alzheimer's disease. The Alzheimer's Disease Cooperative Study. Alzheimer Dis Assoc Disord 11(Suppl 2): 33-39.

36. Üstün TB, Kostanjsek N, Chatterji S, Rehm J (2010) Measuring Health and Disability: Manual for WHO Disability Assessment Schedule (WHODAS 2.0). World Health Organization, $\mathrm{CH}$, Geneva, Switzerland.

37. Federici S, Meloni F, Mancini A, Lauriola M, Olivetti Belardinelli M (2009) World Health Organization Disability Assessment Schedule II: Contribution to the Italian validation. Disabil Rehabil 31(7): 553-564.

38. Federici S, Bracalenti M, Meloni F, Luciano JV (2017) World Health Organization Disability Assessment Schedule 2.0: An International Systematic Review. Disabil Rehabil 39(23): 2347-2380.

39. Cummings JL, Mega M, Gray K, Rosenberg-Thompson S, Carusi DA, et al. (1994) The Neuropsychiatric Inventory: Comprehensive assessment of psychopathology in dementia. Neurology 44(12): 2308-2314.

40. Alexopoulos GS, Abrams RC, Young RC, Shamoian CA (1998) Cornell scale for depression in dementia. Biol Psychiatry 23(3): 271-284.

41. Ballard C, Coope B, Oyebode F, Wilcock G (1997) Depression in Dementia Sufferers-Comparison of Diagnostic Criteria. J Am Geriatr Soc 45(1): $123-124$

42. Cohen Mansfield J (1991) Instruction manual for the Cohen-Mansfield Agitation Inventory (CMAI). Rockville, MA: The Research Institute of the Hebrew Home of Greater Washington.

43. Vespa A, Gori G, Bonaiuto S, Cruciani G, Spazzafumo L (2002) Validation of the Cohen-Mansfield agitation inventory (CMAI-long form) on a sample of Italian demented patients. Arch Gerontol Geriatr 35: 377-383.

44. Vespa A, Gori G, Spazzafumo L (2002) Evaluation of non-pharmacological intervention on antisocial behavior in patients suffering from Alzheimer's disease in a day care center. Arch Gerontol Geriatr 34(1): $1-8$

45. Logsdon RG, Gibbons LE, McCurry SM, Teri L (1999) Quality of life in Alzheimer's Disease: Patient and caregiver reports. Journal of Mental Health and Aging 5(1): 21-32. 
46. Ridder HM (2007) Microanalysis on Selected Video Clips with Focus on Communicative Response in Music Therapy. In: Wosch T, Wigram T, editors. Microanalysis in Music Therapy: Methods, Techniques and Applications for Clinicians, Researchers, Educators and Students. London, UK: Jessica Kingsley Publishers, p. 54-66.

47. Ridder HM, Wigram T, Ottesen AM (2009) A pilot study on the effects of music therapy on frontotemporal dementia-developing a research protocol. Nordic Journal of Music Therapy 18(2):103-132.

48. Svansdottir HB, Snaedal J (2006) Music therapy in moderate and severe dementia of Alzheimer's type: A case-control study. Int Psychogeriatr 18(4): 613-621.

49. Evans P, Forte D, Jacobs C, Fredhoi C, Aitchison E, et al. (2007) Cortisol secretory activity in older people in relation to positive and negative well-being. Psych neuroendocrinology 32(8):922-930.

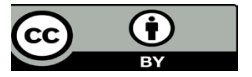

This work is licensed under Creative Commons Attribution 4.0 License

To Submit Your Article Click Here:

DOI: $10.32474 /$ SJPBS.2019.02.000132
50. Takahashi T, Matsushita H (2006) Long-term effects of music therapy on elderly with moderate/severe dementia. J Music Ther 43(4)317-333.

51. Lazarus RS (1947) Psychological Stress and Coping in Adaptation and Illness. The International Journal of Psychiatry in Medicine 5(4): 321333 .

52. Rockwood K, Fay S, Hamilton L, Ross E, Moorhouse P (2014) Good days and bad days in dementia: a qualitative chart review of variable symptom expression. Int Psychogeriatr 26(8): 1239-1246.

53.Zeisel J, Reisberg B, Whitehouse P, Woods R, Verheul A (2016) Ecopsychosocial Interventions in Cognitive Decline and Dementia: A New Terminology and a New Paradigm. Am J Alzheimers Dis Other Demen 31(6): 502 -527.

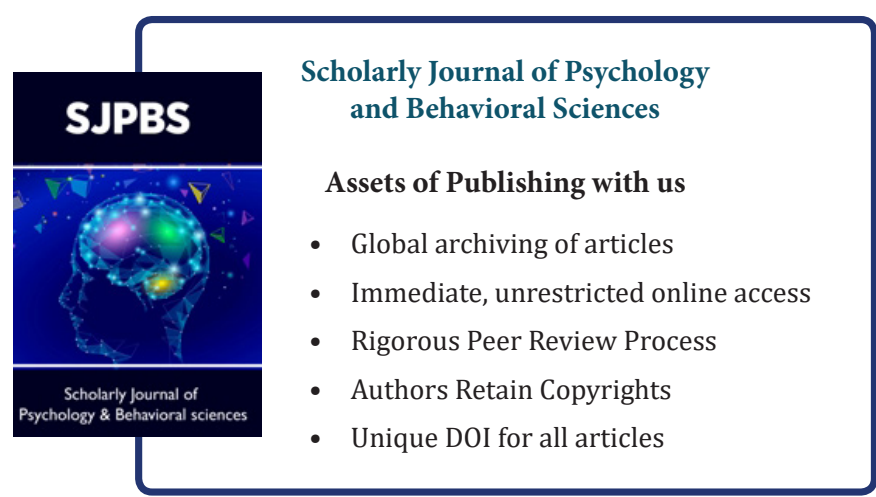

